\title{
CORRELATION BETWEEN CLASSROOM MANAGEMENT AND MATHEMATICS LEARNING OUTCOMES TO FIFTH GRADE STUDENTS OF PUBLIC ELEMENTARY SCHOOLS IN KEBUMEN SUB-DISTRICT IN ACADEMIC YEAR 2019/2020
}

\author{
Aprilia Eka Saputra ${ }^{1}$, Joharman², Rokhmaniyah ${ }^{3}$ \\ Universitas Sebelas Maret \\ apriliaekas04@gmail.com
}

\section{Article History}

accepted 30/8/2021

\begin{abstract}
The study aimed to prove the correlation between classroom management and mathematics learning outcomes to fifth grade students of public elementary schools in Kebumen Sub-District and to determine the contribution of classroom management on mathematics learning outcomes to fifth grade students of public elementary schools in Kebumen Sub-District in academic year 2019/2020. The samples were fifth grade students in twelve public elementary schools in Kebumen Sub-District. The study was quantitative correlational method and the instruments were questionnaires about classroom management and mathematics test. The data analysis used simple correlation. The data validity included validity test and reliability test. The results showed that classroom management had positive and significant correlation on mathematics learning outcomes to fifth grade students of public elementary schools in Kebumen Sub-District. The value of Sig. (1-tailed) was $0.002(<0.005)$ and considered as moderate correlation (0.472). Adjusted $R$ square of classroom management on mathematics learning outcomes was $22 \%$.

Keywords: classroom management, learning outcomes, mathematics.
\end{abstract}

\section{Abstrak}

Tujuan penelitian ini yaitu: 1) membuktikan hubungan pengelolaan kelas dengan hasil belajar matematika siswa kelas V SD Negeri se- Kecamatan Kebumen dan 2) menentukan besar sumbangan pengelolaan kelas terhadap hasil belajar matematika siswa kelas V SD Negeri seKecamatan Kebumen tahun ajaran 2019/2020. Subjek penelitian ini yaitu siswa kelas V SD Negeri se-Kecamatan Kebumen dengan sampel 12 SD Negeri. Jenis pendekatan yang digunakan pada penelitian ini yaitu kuantitatif korelasi dengan instrumen penelitian berupa angket pengelolaan kelas dan soal matematika kelas V. Teknik analisis data menggunakan analisis korelasi sederhana. Keabsahan data diperoleh melalui pengujian validitas dan reliabilitas. Hasil penelitian menunjukan bahwa: (1) pengelolaan kelas berkorelasi positif dan signifikan dengan hasil belajar matematika siswa kelas V SDN se-Kecamatan Kebumen yang dilihat dari nilai Sig. (1-tailed) yaitu $0,002(<0,005)$ dengan tingkat korelasi sedang yaitu 0,472; dan (2) sumbangan variabel pengelolaan kelas terhadap hasil belajar matematika yaitu $22 \%$.

Kata Kunci: Pengelolaan Kelas, Hasil Belajar, Matematika. 


\section{PENDAHULUAN}

Pada saat ini kemajuan teknologi terjadi sangat pesat. Banyak pekerjaan manusia yang digantikan oleh mesin-mesin produksi, akibat dari hal tersebut terjadi persaingan dalam segala aspek kehidupan. Untuk mengatasi tantangan kemajuan teknologi tersebut diperlukan sumber daya manusia yang berkualitas. Sumber daya yang berkualitas dapat dihasilkan salah satunya dengan meningkatkan mutu pendidikan.

Namun, di Indonesia masih terdapat beberapa masalah di bidang pendidikan diantaranya pemerataan pendidikan, kualitas pendidik yang kurang dapat mengikuti perkembangan teknologi, sarana-prasarana yang belum memenuhi standar dan dalam pelaksanaan pendidikan yaitu pengelolaan kelas yang terdapat di sekolah dasar. Hal ini dibuktikan dengan naiknya angka mengulang siswa SD kelas V di Indonesia. Berdasarkan data dari Pusat Data dan Statistik Pendidikan dan Kebudayaan (2016) pada tahun ajaran 2017/2018 angka mengulang sebesar 26.411, sedangkan pada tahun ajaran 2018/2019 terjadi kenaikan angka mengulang menjadi 28.427.

Mutu pendidikan erat hubungannya dengan kegiatan pembelajaran yang dilakukan oleh guru di dalam kelas. Guru memiliki peran yang penting dalam pembelajaran yaitu berperan mengembangkan potensi siswa secara optimal. Menurut Djabidi (2017: 35) kegiatan guru di dalam kelas meliputi dua hal pokok yaitu mengajar dan mengelola kelas.

Djamarah dan Zain (2013: 173) menyatakan bahwa masalah yang dihadapi guru, baik pemula maupun yang sudah berpengalaman adalah pengelolaan kelas. Sebagian besar guru lebih memperhatikan kegiatan mengajar dan kurang memperhatikan pengelolaan kelas. Menurut Karwati dan Priansa (2015: 6) pengelolaan kelas adalah usaha sadar untuk merencanakan, mengorganisasikan, mengaktualisasikan, serta melaksanakan pengawasan atau supervisi terhadap program dan kegiatan yang ada di kelas sehingga proses belajar mengajar dapat berlangsung secara sistematis, efektif, dan efesien, sehingga segala potensi peserta didik mampu dioptimalkan.

Manajemen di sekolah dasar tidak hanya pengaturan belajar, fasilitas fisik dan rutinitas, tetapi menyiapkan kondisi kelas dan lingkungan sekolah agar tercipta kenyamanan dan suasana belajar yang efektif (Tim Dosen Administrasi Pendidikan Universitas Pendidikan Indonesia, 2012: 103). Pengelolaan kelas yang kurang optimal akan mempengaruhi hasil belajar siswa. Annurrahman menyatakan bahwa hasil belajar merupakan hasil akhir pengambilan keputusan mengenai tinggi rendahnya nilai yang diperoleh siswa selama mengikuti proses pembelajaran (Zukira, Harun, dan Jamaludin, 2015: 2). Hasil belajar dikatakan tinggi apabila tingkat kemampuan siswa bertambah dari hasil sebelumnya. Suatu proses belajar mengajar pada akhirnya akan menghasilkan kemampuan siswa yang mencangkup aspek pengetahuan, sikap, dan keterampilan. Dalam arti bahwa perubahan kemampuan merupakan indikator untuk mengetahui hasil belajar siswa.

Salah satu mata pelajaran yang sering dianggap sulit oleh siswa yaitu matematika. Matematika merupakan disiplin ilmu yang dapat meningkatkan kemampuan berpikir, beragumentasi, memberikan kontribusi dalam penyelesaian masalah di kehidupan sehari-hari, serta mendukung perkembangan ilmu pengetahuan dan teknologi (Susanto, 2016: 186).

Pada penelitian ini, peneliti menggunakan tes untuk mengetahui hasil belajar matematika siswa kelas V SD. Tes yang digunakan yaitu tes dalam bentuk pilihan ganda. Adapun indikator hasil belajar matematika yang peneliti gunakan yaitu materi matematika kelas $\mathrm{V}$ semester I yang dibuat menjadi soal dengan bentuk pilihan ganda. Sedangkan untuk mengetahui pengelolaan kelas peneliti menggunakan angket .Indikator yang digunakan untuk mengetahui pengelolaan kelas dibagi menjadi dua. Pertama penciptaan dan pemeliharaan kondisi belajar yang optimal berupa mengatur tempat duduk dan tata ruang yang sesuai dengan strategi yang digunakan, 
menentukan alokasi penggunaan waktu belajar-mengajar, menentukan cara mengorganisasi siswa agar terlibat secara aktif dalam kegiatan belajar mengajar, menunjukkan sikap tanggap, interaksi yang baik dengan siswa, membagi perhatian, memusatkan perhatian kelompok, memberikan petunjuk-petunjuk yang jelas, menegur. Kedua pengembalian kondisi belajar yang optimal berupa memodifikasi tingkah laku, pengelolaan kelompok, menemukan dan memecahkan tingkah laku yang menimbulkan masalah.

Rumusan masalah pada penelitian ini yaitu adakah hubungan pengelolaan kelas dengan hasil belajar matematika siswa kelas V SD Negeri se-Kecamatan Kebumen, dan seberapa besar sumbangan pengelolaan kelas terhadap hasil belajar matematika siswa kelas V SD Negeri se-Kecamatan Kebumen tahun ajaran 2019/2020?

Tujuan penelitian ini yaitu untuk membuktikan hubungan pengelolaan kelas dengan hasil belajar matematika siswa V SD Negeri se-Kecamatan Kebumen dan menentukan besar sumbangan pengelolaan kelas terhadap hasil belajar matematika siswa kelas V SD Negeri se-Kecamatan Kebumen tahun ajaran 2019/2020.

\section{METODE}

Metode yang digunakan dalam penelitian ini adalah metode korelasi kuantitatif dengan menggunakan dua instrumen penelitian yaitu angket pengelolaan kelas dan soal hasil belajar matematika. Populasi penelitian ini yaitu seluruh siswa kelas V SDN di-Kecamatan Kebumen sedangkan untuk sampel penelitian yaitu siswa kelas $V$ di dua belas SDN di-Kecamatan Kebumen yang diperoleh dari perhitungan menggunakan rumus Sangadji dan Sopiah (2010) yaitu:

$$
\begin{array}{cl|l|}
\cline { 3 - 3 } & & \mathrm{n}=\frac{\mathrm{N}}{\mathrm{N} \cdot \mathrm{e}^{2}+1} \\
\cline { 3 - 3 } \text { Keterangan: } & \mathrm{n} & =\text { jumlah sampel } \\
& \mathrm{N} & =\text { jumlah populasi } \\
& \mathrm{e} 2 & \text { = presisi yang ditetapkan }
\end{array}
$$

Diperoleh dua belas SD Negeri yang meliputi SDN 2 Kebumen, SDN 7 Kebumen, SDN 4 Kutosari, SDN 2 Bumirejo, SDN 3 Tamanwinangun, SDN Murtirejo, SDN Mengkowo, SDN 2 Tanahsari, SDN 1 Bandung, SDN Candimulyo, SDN Jemur, dan SDN Kawedusan. Data yang sudah didapat kemudian dianalisis menggunakan analisis korelasi dan regresi untuk menentukan adakah hubungan pengelolaan kelas dengan hasil belajar matematika siswa kelas V SD Negeri se-Kecamatan Kebumen dan seberapa besar sumbangan pengelolaan kelas terhadap hasil belajar matematika siswa kelas V SD Negeri se-Kecamatan Kebumen.

\section{HASIL DAN PEMBAHASAN}

Data yang diperoleh peneliti yaitu data hasil belajar matematika yang berjenis data ordinal dan data angket pengelolaan kelas yang berjenis data interval. Sebelum dilakukan perhitungan, data angket yang berupa data interval dirubah terlebih dahulu menjadi data ordinal menggunakan bantuan aplikasi metode suksesif interval (MSI). Dari perhitungan data menggunakan aplikasi SPSS diperoleh perhitungan deskripsi hasil belajar matematika siswa yaitu

Berdasarkan perhitungan dengan bantuan aplikasi SPSS di dapatkan data jumlah sampel penelitian hasil belajar matematika yaitu 275 siswa. Nilai rata-rata data hasil belajar matematika yaitu 24,51. Median atau nilai tengah data hasil belajar matematika yaitu 25,00 . Modus atau nilai yang sering muncul pada data hasil belajar 
matematika yaitu 26. Simpangan bakunya (standard deviation) yaitu 7,070. Sementara range (variance) data hasil belajar matematika yaitu 49,981.

Kemiringan (skewness) kurva yaitu -0,076. Nilai kurtosis (keruncingan kurva) yaitu -0.839. Rentang data hasil belajar matematika yaitu 31. Nilai minimum yang didapatkan dari hasil penelitian untuk penelitian hasul belajar matematika yaitu 6 , sedangkan nilai maksimumnya yaitu 37 . Jumlah skor seluruh data hasil belajar matematika yaitu 6739 .

Berdasarkan perhitungan dengan bantuan aplikasi SPSS di dapatkan data jumlah sampel penelitian pengelolaan kelas yaitu 275 siswa. Nilai rata-rata yaitu 90,55. Median atau nilai tengah yaitu 90,42. Modus atau nilai yang sering muncul pada data tersebut yaitu 85,97. Simpangan bakunya (standard deviation) yaitu 11,48. Ragam (variance) yaitu 131,79.

Kemiringan (skewness) kurva yaitu, -0,354. Keruncingan (kurtosis) kurvanya yaitu 0,179 . Rentang data pengelolaan kelas yaitu 67,9 . Nilai minimumnya yaitu 44,742, sedangkan nilai maksimumnya yaitu 112,658. Jumlah skor seluruh data pengelolaan kelas yaitu 24.900,972.

Uji prasyarat penelitian ini semuanya terpenuhi. Yang pertama yaitu uji normalitas pada penelitian ini di peroleh nilai sig. sebesar 0,054 untuk hasil belajar matematika dan 0,200 untuk angket pengelolaan kelas kedua nilai sig. tersebut $>$ dari 0,05 artinya populasi/ data berdistribusi normal. Yang kedua yaitu uji Linieritas, pada uji linieritas diperoleh nilai Sig. Deviation from Linearity sebesar 0,116. nilai Sig. Deviation from Linearity $(0,116)>0,05$ artinya terdapat hubungan linier antara pengelolaan kelas dan hasil belajar matematika

Tabel 1. Hasil Analisis Korelasi Pengelolaan Kelas dengan Hasil Belajar Matematika

\section{Correlations}

\begin{tabular}{llr|r} 
& & \multicolumn{1}{c}{$\begin{array}{c}\text { HASIL } \\
\text { BELAJAR }\end{array}$} & $\begin{array}{r}\text { PENGELOLAA } \\
\text { N KELAS }\end{array}$ \\
\hline HASIL BELAJAR & Pearson Correlation & 1 & $.472^{* *}$ \\
\cline { 2 - 4 } & Sig. (1-tailed) & 275 & .002 \\
\cline { 2 - 4 } & N & $.472^{* *}$ & 275 \\
\hline \multirow{2}{*}{ PENGELOLAAN KELAS } & Pearson Correlation & .002 & 1 \\
\cline { 2 - 4 } & Sig. (1-tailed) & 275 & 275 \\
\cline { 2 - 4 } & N & & \\
\hline
\end{tabular}

${ }^{\star *}$. Correlation is significant at the 0.01 level (1-tailed).

Uji hipotesis pada penelitian ini terdapat 2. Yang pertama uji Korelasi Pengelolaan Kelas dan Hasil Belajar Matematika Kelas V. bedasrkan tabel 1 di atas dapat diketahui nilai signifikansi (1-tailed) penelitian ini sebesar 0,002 < 0,05 yang berarti bahwa ada korelasi positif antara pengelolaan kelas dan hasil belajar matematika siswa kelas V SDN se-Kecamatan Kebumen. Sedangkan untuk analisis korelasi antara variabel pengelolaan kelas dan hasil belajar matematika didapatkan $r$ hitung sebesar 0,472 . Dengan $r$ tabel sebesar 0,118 . Oleh karena itu, nilai $r$ hitung $(0,472)>r$ tabel $(0,118)$ artinya terdapat hubungan positif antara pengelolaan kelas dengan hasil belajar matematika. Kedua yaitu sumbangan efektif yang mana dapat dihitung menggunakan rumus $S E=S R \times R^{2}$. Berdasarkan hasil perhitungan didapatkan nilai $\mathrm{SR}$ dan $\mathrm{R}^{2}$ sebesar $100 \%$ dan 0,22 . Jadi sumbangan efektif dapat dihitung yaitu 
SE $=100 \% \times 0,22$

$\mathrm{SE}=22 \%$

Berdasarkan hasil perhitungan tersebut, dapat diketahui bahwa sumbangan efektif dari pengelolaan kelas dapat berperan dalam meningkatkan hasil belajar matematika sebesar $22 \%$, sedangkan sisanya sebesar $78 \%$ dipengaruhi oleh faktor lain.

\section{SIMPULAN}

Pengelolaan kelas berkorelasi positif dan signifikan dengan hasil belajar matematika siswa kelas $\mathrm{V}$ SDN se-Kecamatan Kebumen dengan tingkat korelasi sedang yaitu 0,472 .

Sumbangan variabel pengelolaan kelas terhadap hasil belajar matematika yaitu $22 \%$. Terdapat hubungan yang positif dan signifikan antara pengelolaan kelas dengan hasil belajar matematika. Semakin baik pengelolaan kelas, maka semakin tinggi hasil belajar matematika siswa. Begitu pun sebaliknua, semakin buruk pengelolaan kelas, maka akan semakin rendah hasil belajar siswa. Oleh karena itu, penting untuk melakukan pengelolaan kelas pada setiap pembelajaran.

Pengelolaan kelas dapat dilakukan dengan berbagai cara. Berkaitan dengan hasil penelitian yang telah dicapai, peneliti mengajukan saran sebagai berikut: 1) menata tempat duduk; 2) mengatasi gangguan dari dalam dan luar kelas; 3) menetapkan aturan/prosedur; 4) pengaturan fasilitas belajar, dan lain-lain. Melalui upaya-upaya tersebut diharapkan dapat meningkatkan pengelolaan kelas sehingga diharapkan hasil belajar siswa dapat meningkat. 


\section{DAFTAR PUSTAKA}

Djabidi, F. (2017). Manajemen Pengelolaan Kelas. Malang: Madani.

Djamarah, S. B \& Zain, A. (2013). Strategi Belajar Mengajar. Jakarta: PT Rineka Cipta.

Pusat Data dan Statistik Pendidikan dan Kebudayaan. (2016). Statistik pendidikan: sekolah dasar. Jakarta. Diperoleh 30 Desember 2019, dari http://statistik.data.kemdikbud.go.id/

Karwati, E \& Priansa, D. J. (2015). Manajemen Kelas. Bandung: Alfabeta

Sangadji , Etta Mamang \& Sopiah. (2010). Metodologi Penelitian-Pendekatan Praktis dalam Penelitian,Yogyakarta,ANDI

Susanto, A. (2016). Teori Belajar dan Pembelajaran di Sekolah Dasar. Jakarta: Prenadamedia Group.

Tim Dosen Administrasi Pendidikan Universitas Pendidikan Indonesia. (2012). Manajemen Pendidikan. Bandung: Alfabeta.

Zukira., Harun, A. H., \& Jamaluddin. (2015). Meningkatkan Hasil Belajar Siswa Kelas III Sekolah Dasar Alkhairaat Toweran Melalui Model Pembelajaran Kooperatif Tipe Number Head Together (NHT) Pada Mata Pelajaran PKn. Jurnal Kreatif Tadulako Online Vol. 3 No. 4. Diperoleh 22 Februari 2020 dari http://jurnal.untad.ac.id/jurnal/index.php/JKTO/article/view/3062/2135 